\title{
Clinical characteristics and prognostic factors of malignant fibrous histiocytoma of bone: a SEER population-based study
}

\author{
Lin $\mathrm{Qi}^{1,2}$, Chao Tu ${ }^{1,2}$, Xiaolei Ren ${ }^{1,2}$, Ruiqi Chen ${ }^{1,2}$, Lu Wan ${ }^{1,2}$, Chenghao Zhang ${ }^{1,2}$, Zhihong Li ${ }^{1,2}$ \\ ${ }^{1}$ Department of Orthopedics, ${ }^{2}$ Hunan Key Laboratory of Tumor Models and Individualized Medicine, The Second Xiangya Hospital, Central South \\ University, Changsha 410011, China \\ Contributions: (I) Conception and design: L Qi, Z Li; (II) Administrative support: C Tu, Z Li; (III) Provision of study materials or patients: L Qi, C \\ Tu, X Ren; (IV) Collection and assembly of data: L Qi, R Chen; (V) Data analysis and interpretation: L Qi, C Tu, X Ren, L Wan; (VI) Manuscript \\ writing: All authors; (VII) Final approval of manuscript: All authors. \\ Correspondence to: Zhihong Li. Department of Orthopedics, Hunan Key Laboratory of Tumor Models and Individualized Medicine, The Second \\ Xiangya Hospital, Central South University, 139 Renmin Road, Changsha 410011, China. Email: lizhihong@csu.edu.cn.
}

Background: Malignant fibrous histiocytoma of bone (MFH-B) is an extremely rare type of bone tumor. We aimed to analyze the clinical characteristics of MFH-B and establish nomograms that predict the prognosis of patients with MFH-B based on prognostic factors.

Methods: A total of 250 patients diagnosed with MFH-B were included from the Surveillance, Epidemiology, and End Results (SEER) database. Kaplan-Meier curves and log-rank tests were conducted. Potential prognostic factors were identified using univariate and multivariate Cox regression analysis. Nomograms that predict 3- and 5-year overall survival (OS) and cancer-specific survival (CSS) were further developed and internally validated.

Results: The multivariate analysis suggested that OS of patients was associated with age $\geq 57$ years [hazard ratio (HR), 1.916; 95\% confidence interval (CI), 1.329-2.761; $\mathrm{P}<0.001$ ], pelvic bones (HR, 1.742; 95\% CI, 1.024-2.961; $\mathrm{P}=0.040$ ) and other tumor sites (HR, 2.498; 95\% CI, 1.515-4.120; $\mathrm{P}<0.001)$, Grade III/IV (HR, 1.750; 95\% CI, 1.002-3.056; $\mathrm{P}=0.049)$, distant tumor stage (HR, 2.100; 95\% CI, 1.351-3.263; $\mathrm{P}=0.001)$, tumor size $\geq 66 \mathrm{~mm}(\mathrm{HR}, 2.629 ; 95 \% \mathrm{CI}, 1.747-3.959 ; \mathrm{P}<0.001)$ and no surgery $(\mathrm{HR}, 2.134 ; 95 \% \mathrm{CI}$, 1.380-3.300; $\mathrm{P}=0.001)$. We then developed nomograms based on the prognostic factors. The concordance index (C-index) of nomograms for OS and CSS were 0.74 (95\% CI, 0.70-0.77) and 0.74 (95\% CI, 0.70-0.78). Calibration plots suggested optimal concordance between the predictive outcomes of nomograms with the actual survival.

Conclusions: This is the first sizable study that analyzed clinical characteristics and prognostic factors of MFH-B. The nomograms we established for MFH-B were effective tools to predict prognosis of individual patients. These tools can also help doctors identify mortality risk.

Keywords: Malignant fibrous histiocytoma (MFH); prognosis; Surveillance, Epidemiology, and End Results program (SEER program); nomogram

Submitted Oct 24, 2019. Accepted for publication Jan 07, 2020.

doi: $10.21037 /$ tcr.2020.01.56

View this article at: http://dx.doi.org/10.21037/tcr.2020.01.56

\section{Introduction}

Malignant fibrous histiocytoma of bone (MFH-B), firstly reported by Feldman and Norman in 1972, is one extremely rare type of bone tumor and accounts for only $3 \%$ to $8 \%$ of all bone tumors $(1,2)$. The primary site of most MFH-B was the appendicular skeleton (3). This aggressive tumor is characterized by high rates of recurrence and metastasis (4). Before chemotherapy was used as the convention treatment, the MFH-B leaded to unfavorable prognosis with a 5-year 
survival rate of $15 \%$ (5). Neoadjuvant chemotherapy then played a critical part in the treatment of MFH-B, and it was reported that 5 -year disease-free survival increased to nearly $50 \%(6)$

Many studies have explored the prognostic factors of MFH-B in the past few decades. Age, tumor stage, the depth of tumor, tumor size, the use of surgery and chemotherapy and surgical margin might be associated with the prognosis of patients with MFH-B (6-9). However, the number of relevant studies on MFH-B were extremely limited due to the extremely low incidence of this disease. Besides, single prognostic factor is insufficient to predict the prognosis of MFH-B. Therefore, it is necessary to analyze prognostic factors of MFH-B based on relatively large sample size, and establish a clinical prediction model integrating significant prognostic factors, which could predict the survival of individual patient with MFH-B.

Nomogram is an effective and visible prognostic tool to predict individual prognosis by integrating all significant prognostic factors. The effectiveness of nomogram as a clinical prediction model has been proved in many malignant tumors $(10,11)$. The Surveillance, Epidemiology, and End Results (SEER) database has been collecting cancer data since 1973 in 18 population-based cancer registries, which included nearly $30 \%$ of population in the United States (12). In the current study, we aimed to construct nomograms of MFH-B by integrating all significant prognostic factors based on SEER database, which could make prediction about the survival rate of individual patient with MFH-B.

\section{Methods}

\section{Data sources and patient screening}

SEER database based on 18 cancer registries from 1973 to 2016 was applied to collect data (12). The collection of data could be carried out without informed consent of patients, as there was no identifying information of individual patient in the SEER database. The research data could be accessed with the permission of the national cancer institute.

The selection of patients was performed according to the following inclusion criteria: (I) diagnosis of malignant fibrous histiocytoma $(\mathrm{MFH})$ with ICD-O-3 histology code = 8830; (II) sites limited to bone with ICD-O-3/WHO 2008 site code $=\mathrm{C} 40.0-\mathrm{C} 41.9$ as the primary malignancy; (III) confirmation of positive histology; (IV) known specific survival time along with causes of death after diagnosis.

\section{Prognostic factors}

Data including race, sex, age at diagnosis, exact year at diagnosis, marital status, primary tumor site, tumor stage, tumor size, tumor grade, surgical operation, radiotherapy, chemotherapy and survival time were selected from this national-level database. Multiple imputation by chained equations (MICE) were introduced to handle missing data of tumor size, tumor grade and tumor stage for all related characteristics (13). Five imputed data sets were generated, and Rubin's rules were followed in the subsequent analysis (14). Cut-off points of the age at diagnosis and tumor size of patients based on overall survival (OS) were calculated by $\mathrm{X}$-tile program, which is an effective tool to stratify tumorrelated parameters (15). The optimal cut-off point of the age at diagnosis was 57 years while that of tumor size was 66 millimeter (mm) (Figure 1). The tumor sites were divided into four separate groups including the extremities (bones of upper and lower limbs), the spine, the pelvic bones and others. There were four different degrees of tumor grades in the data collected, including Grade I, II, III and IV. The malignancy that was well differentiated was defined as Grade I. The tumor differentiating moderately was defined as Grade II. Tumor with poor differentiation was defined as Grade III while tumor in Grade IV demonstrated that it was undifferentiated or anaplastic. We divided the grades of differentiation of MFH-B into two different groups in our study. SEER historic stages were classified as localized, regional and distant in line with Summary Stage 2018: Codes and Coding Instructions (16). The localized tumor was defined as the tumor confined to cortex of bone while the regional tumor extending beyond the cortex of bone without any distant metastases. The bone tumor in the distant stage was accompanied with distant metastases and further contiguous extension.

\section{Statistical analysis}

The primary endpoints in our current study were OS and cancer-specific survival (CSS). The OS was defined as the period of time from the day that the patient was diagnosed as MFH-B to death because of any cause. The CCS was the period from the date of diagnostic confirmation to death only from MFH-B. Censored observations were defined as the surviving patients at the end of follow-up period.

Demographic factors (race, sex, age, marital status, and exact year at diagnosis), tumor-related variables (primary 

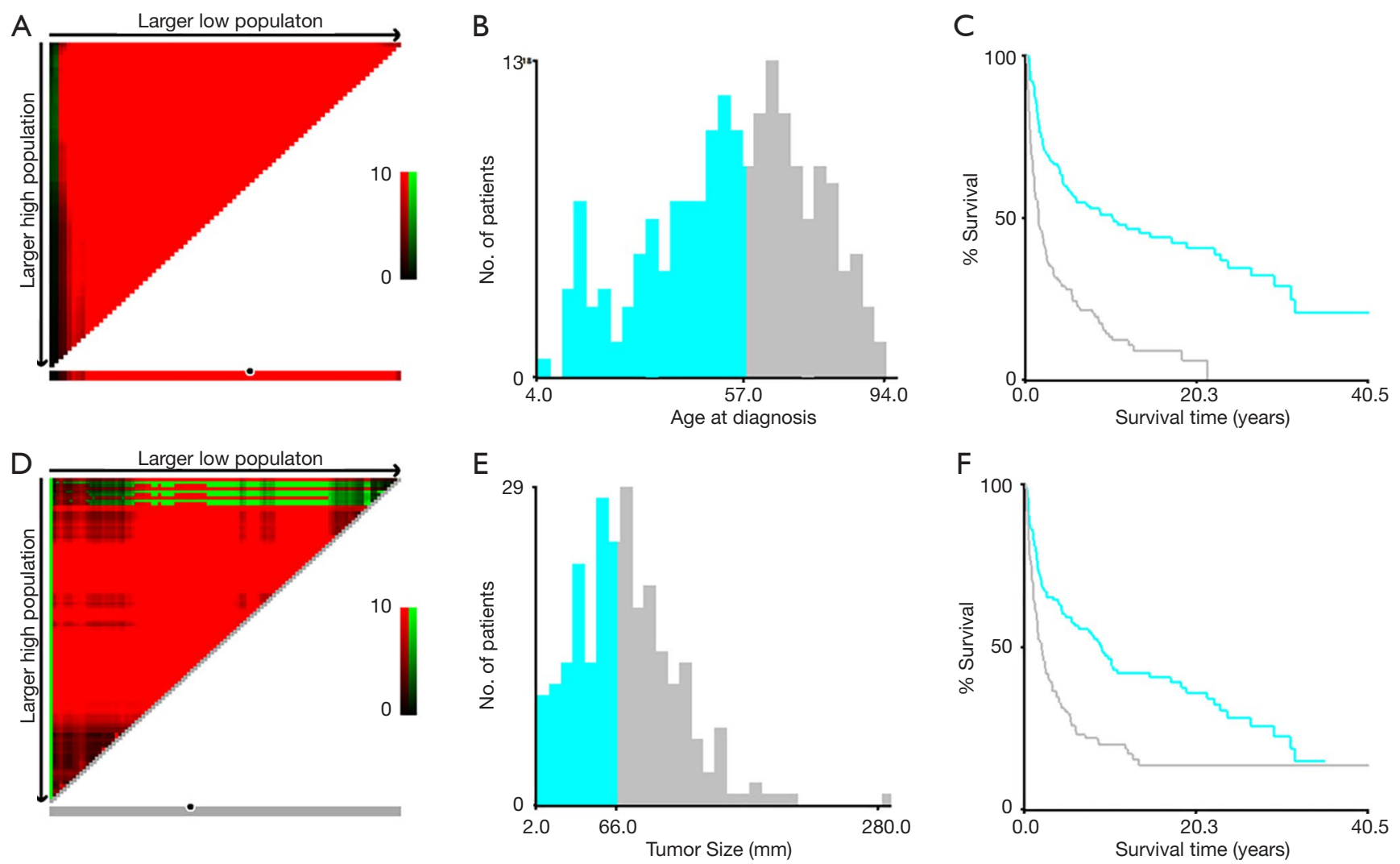

Figure 1 Identification of optimal cut-off points of age at diagnosis (A,B,C) and tumor size (D,E,F) by the X-tile. (A,D) The cut-off points of age at diagnosis and tumor size were determined by the software with the black dots; histograms (B,E) and Kaplan-Meier curves (C,F) were established according to the cut-off points determined. Optimal cut-off points of age at diagnosis and tumor size were 57 years and $66 \mathrm{~mm}$, respectively.

tumor site, grade, stage and size) and therapy methods (surgery, radiotherapy and chemotherapy) were included in the univariate COX analysis for potential prognostic factors. OS and CSS were analyzed by Kaplan-Meier methods, 3- and 5-year OS and CSS were estimated with Kaplan-Meier curves. Log-rank tests were performed to analyze differences of OS or CSS among various groups. Variables that were statistically significant in univariate analysis were entered into multivariate COX analysis. Statically significant prognostic factors were identified through the whole process. Hazard ratio (HR) along with $95 \%$ confidence interval $(\mathrm{CI})$ were also calculated. $\mathrm{P}$ value $\leq 0.05$ was regarded with statistical significance.

\section{Construction and validation of the nomograms}

Nomograms predicting 3- and 5-year OS and CSS were established according to statically significant prognostic factors identified in the multivariate analysis. The internal validation of nomograms was tested by the discrimination and calibration with 2000 sets of bootstraps. Receiver operating characteristic (ROC) curves and Harrell's concordance index (C-index) were applied for measuring the predictive power of nomograms. The maximum of C-index value is 1.0 , and the minimum of that is 0.5 (17). The predictive power of nomograms increases with the C-index rising. Calibration plots were also drawn to make comparisons between the prediction of outcomes by nomograms and the actual survival. We screened the data in the SEER database using SEER*Stat software version 8.3.5 (National Cancer Institute, Bethesda, MD, USA). Optimal cut-off points were calculated via $\mathrm{X}$-tile program (Yale University, New Haven, CT, USA). Univariate and multivariate Cox regression analysis were performed by Statistical Package for the Social Sciences (SPSS), version 24 for Windows (IBM, Armonk, New York, USA). Graphs 


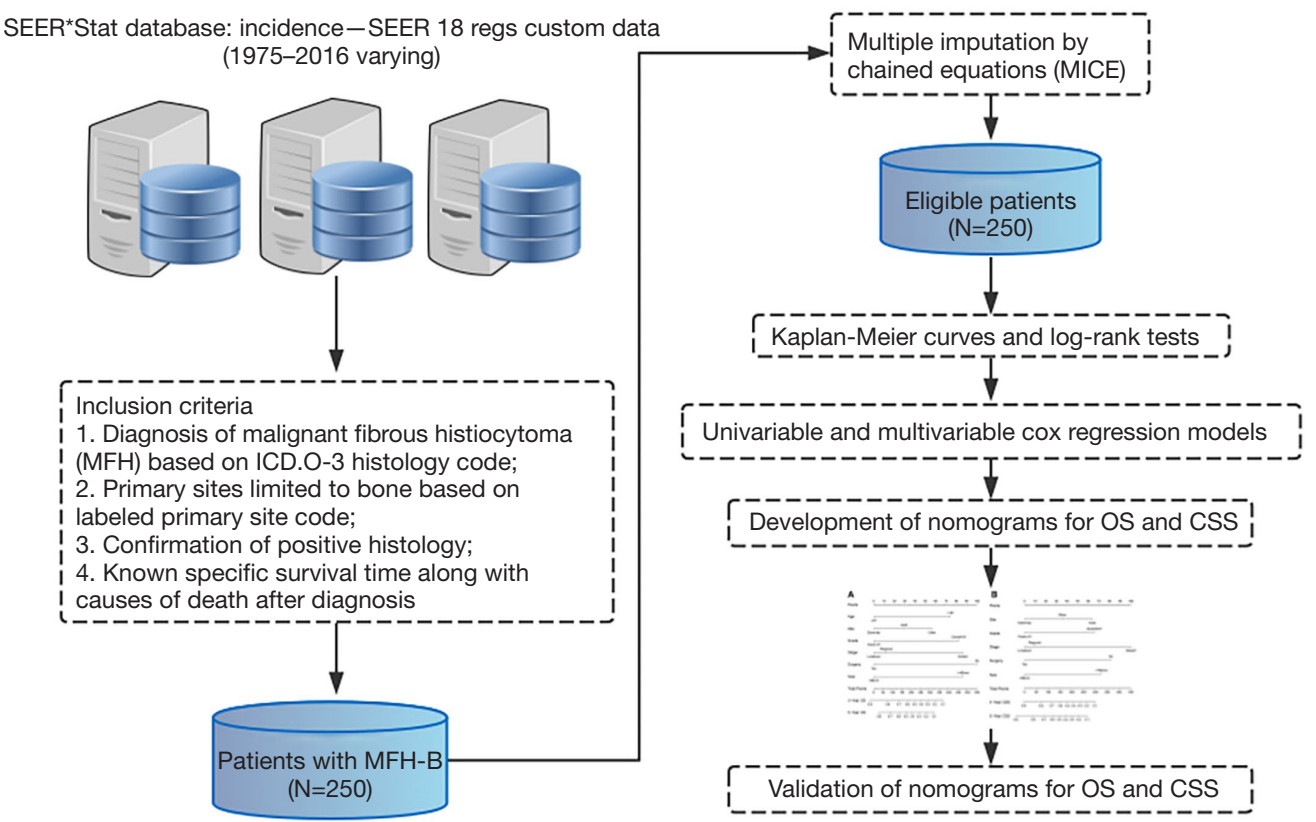

Figure 2 Study design. Data of patients with a histologically confirmed diagnosis of MFH-B were extracted from the SEER database (1975-2016), and then were analyzed according to the study design. MFH-B, malignant fibrous histiocytoma of bone; SEER, Surveillance Epidemiology and End Results.

were drawn by GraphPad Prism 8 software (GraphPad Software, Inc., La Jolla, CA, USA). Construction and validation of nomograms were performed based on the $R$ version 3.5.3 (http://www.r-project.org/) with rms Package.

\section{Results}

\section{Basic characteristics of included patients}

Based on the inclusion criteria, a total of 250 patients with MFH-B confirmed by histology from 1975 to 2016 were retrieved from the SEER database (Figure 2). The median age of patients enrolled was 56 (range, 4-94) years. As is shown in the Table 1, male accounts for $52 \%$ of total number of patients and 120 patients (48\%) were female. Most patients were married (133/250, 53.2\%) at diagnosis, while 63 patients were single and 54 patients were divorced or widowed at that time. The most common primary location of MFH-B was the extremity (188/250, 75.2\%), and only $2.8 \%$ of patients (7/250) had MFH-B in the spine as the primary site. The differentiation of MFH-B varied significantly, with nearly $86.8 \%$ of MFH-B (217/250) poorly differentiated or even undifferentiated (Grade III/IV). In respect to tumor stage, approximately $40.4 \%$ of tumors $(101 / 250)$ were regional, followed by localized tumors $(87 / 250,34.8 \%)$ and distant tumors $(62 / 250,24.8 \%)$. Nearly $53.6 \%$ of tumors (134/250) were over $66 \mathrm{~mm}$. One hundred and eighty-nine patients $(75.6 \%)$ with MFH-B received surgical management, while chemotherapy was used in 121 patients (48.4\%) and $19.2 \%$ of patients (48/250) were given radiation therapy. There were 170 patients with specific surgical types including limb salvage and amputation, most of whom underwent limb salvage (135/170). The median survival time of patients included in the study was 32.5 (range, 1-486) months. At the end of follow-up period, 135 patients (54\%) died from MFH-B and 46 patients died from other causes.

\section{Prognostic variables}

Totally 250 patients with MFH-B were entered into the univariate and multivariate survival analyses, so as to identify independent prognostic factors of OS and CSS. Three- and 5 -year OS of patients with MFH-B were 51.2\% (95\% CI, $44.9-57.5 \%$ ) and $43.5 \%$ (95\% CI, 37.2-49.8\%). Three- and 
Table 1 Basic variables of patients with MFH-B in SEER database

\begin{tabular}{|c|c|c|}
\hline Characteristics & $\begin{array}{c}\text { Number of } \\
\text { patients }\end{array}$ & Percentage (\%) \\
\hline \multicolumn{3}{|l|}{ Race } \\
\hline White & 211 & 84.4 \\
\hline Other & 14 & 5.6 \\
\hline Black & 25 & 10.0 \\
\hline \multicolumn{3}{|l|}{ Sex } \\
\hline Male & 130 & 52.0 \\
\hline Female & 120 & 48.0 \\
\hline \multicolumn{3}{|c|}{ Age at diagnosis (years) } \\
\hline$<57$ & 127 & 50.8 \\
\hline$\geq 57$ & 123 & 49.2 \\
\hline \multicolumn{3}{|l|}{ Year of diagnosis } \\
\hline 1970s & 15 & 6.0 \\
\hline 1980s & 59 & 23.6 \\
\hline 1990s & 55 & 22.0 \\
\hline $2000 s$ & 93 & 37.2 \\
\hline 2010s & 28 & 11.2 \\
\hline \multicolumn{3}{|c|}{ Marital status at diagnosis } \\
\hline Divorced/widowed & 54 & 21.6 \\
\hline Single & 63 & 25.2 \\
\hline Married & 133 & 53.2 \\
\hline \multicolumn{3}{|l|}{ Primary tumor site } \\
\hline Extremity & 188 & 75.2 \\
\hline Spine & 7 & 2.8 \\
\hline Pelvic bones & 24 & 9.6 \\
\hline Other & 31 & 12.4 \\
\hline \multicolumn{3}{|l|}{ Tumor grade } \\
\hline Grade I/II & 33 & 13.2 \\
\hline Grade III/IV & 217 & 86.8 \\
\hline \multicolumn{3}{|l|}{ Tumor stage } \\
\hline Localized & 87 & 34.8 \\
\hline Regional & 101 & 40.4 \\
\hline Distant & 62 & 24.8 \\
\hline
\end{tabular}

Table 1 (Continued)
Table 1 (Continued)

\begin{tabular}{lcc}
\hline Characteristics & $\begin{array}{c}\text { Number of } \\
\text { patients }\end{array}$ & Percentage (\%) \\
\hline $\begin{array}{l}\text { Tumor size (mm) } \\
<66\end{array}$ & 116 & 46.4 \\
$\geq 66$ & 134 & 53.6 \\
Surgery & 189 & \\
Yes & 61 & 75.6 \\
No & & 24.4 \\
Radiation therapy & 48 & 19.2 \\
Yes & 202 & 80.8 \\
No & & \\
Chemotherapy & 121 & 48.4 \\
Yes & 129 & 51.6 \\
No
\end{tabular}

$\mathrm{MFH}-\mathrm{B}$, malignant fibrous histiocytoma of bone; SEER, Surveillance Epidemiology and End Results.

5-year CSS of that were 55.6\% (95\% CI, 49.1-62.0\%) and $47.2 \%$ (95\% CI, 40.7-53.7\%). As illustrated in Table 2, after controlling for age at diagnosis, year of diagnosis, marital status, primary tumor site, tumor grade, tumor size, surgery and chemotherapy, OS of patients was associated with age $\geq 57$ years (HR, 1.916; 95\% CI, 1.329-2.761; $\mathrm{P}<0.001$ ), pelvic bones (HR, 1.742; 95\% CI, 1.024-2.961; $\mathrm{P}=0.040$ ) and other tumor sites (HR, 2.498; 95\% CI, 1.515-4.120; $\mathrm{P}<0.001$ ), Grade III/IV (HR, 1.750; 95\% CI, 1.002-3.056; $\mathrm{P}=0.049)$, distant tumor stage (HR, 2.100; 95\% CI, 1.3513.263; $\mathrm{P}=0.001$ ), tumor size $\geq 66 \mathrm{~mm}(\mathrm{HR}, 2.629 ; 95 \% \mathrm{CI}$, $1.747-3.959 ; \mathrm{P}<0.001)$ and no surgery $(\mathrm{HR}, 2.134 ; 95 \% \mathrm{CI}$, 1.380-3.300; $\mathrm{P}=0.001)$. Likewise, the multivariate analysis for CSS showed that pelvic bones (HR, 2.331; 95\% CI, 1.307-4.157; $\mathrm{P}=0.004$ ), Grade III/IV (HR, 2.087; 95\% CI, 1.024-4.255, $\mathrm{P}=0.043)$, distant tumor stage (HR, 2.662; 95\% CI, 1.623-4.367; $\mathrm{P}<0.001$ ), tumor size $\geq 66 \mathrm{~mm}$ (HR, 2.308; 95\% CI, 1.458-3.654; $\mathrm{P}<0.001$ ), and no surgery (HR, $2.273 ; 95 \%$ CI, 1.392-3.710; $\mathrm{P}=0.001)$ were statistically significant (Table 3). The survival curves of independent prognostic factors were illustrated in Figure S1,S2. There was no significant difference in OS and CSS between limb salvage and amputation (Figure S3). The OS and CSS of 
Table 2 Univariate and multivariate analyses of OS in patients with MFH-B

\begin{tabular}{|c|c|c|c|c|}
\hline Characteristics & \multicolumn{2}{|c|}{ Univariate analysis } & \multicolumn{2}{|c|}{ Multivariate analysis } \\
\hline \multicolumn{5}{|l|}{ Race } \\
\hline White & Reference & & & \\
\hline Other & $1.582(0.854-2.929)$ & 0.144 & & \\
\hline \multicolumn{5}{|l|}{ Sex } \\
\hline Male & Reference & & & \\
\hline Female & $0.870(0.649-1.167)$ & 0.354 & & \\
\hline \multicolumn{5}{|c|}{ Age at diagnosis (years) } \\
\hline \multicolumn{5}{|l|}{ Year of diagnosis } \\
\hline $1970 s$ & Reference & & Reference & \\
\hline 1980s & $0.519(0.285-0.945)$ & 0.032 & $1.397(0.676-2.885)$ & 0.367 \\
\hline 1990s & $0.597(0.326-1.093)$ & 0.095 & $1.732(0.805-3.728)$ & 0.160 \\
\hline $2000 s$ & $0.436(0.241-0.787)$ & 0.006 & $1.040(0.507-2.133)$ & 0.914 \\
\hline 2010s & $0.486(0.231-1.025)$ & 0.486 & $1.408(0.602-3.297)$ & 0.430 \\
\hline \multicolumn{5}{|c|}{ Marital status at diagnosis } \\
\hline Divorced/widowed & Reference & & Reference & \\
\hline Spine & $1.219(0.497-2.992)$ & 0.666 & $0.859(0.325-2.274)$ & 0.760 \\
\hline Pelvic bones & $1.796(1.140-2.829)$ & 0.012 & $1.742(1.024-2.961)$ & 0.040 \\
\hline Other & $1.554(1.031-2.343)$ & 0.035 & $2.498(1.515-4.120)$ & $<0.001$ \\
\hline \multicolumn{5}{|l|}{ Tumor grade } \\
\hline Grade I/II & Reference & & Reference & \\
\hline Grade III/IV & $1.597(1.010-2.542)$ & 0.045 & $1.750(1.002-3.056)$ & 0.049 \\
\hline \multicolumn{5}{|l|}{ Tumor stage } \\
\hline Localized & Reference & & Reference & \\
\hline Regional & $1.150(0.801-1.649)$ & 0.449 & $0.953(0.633-1.434)$ & 0.817 \\
\hline Distant & $3.993(2.728-5.843)$ & $<0.001$ & $2.100(1.351-3.263)$ & 0.001 \\
\hline
\end{tabular}

Table 2 (Continued) 
Table 2 (Continued)

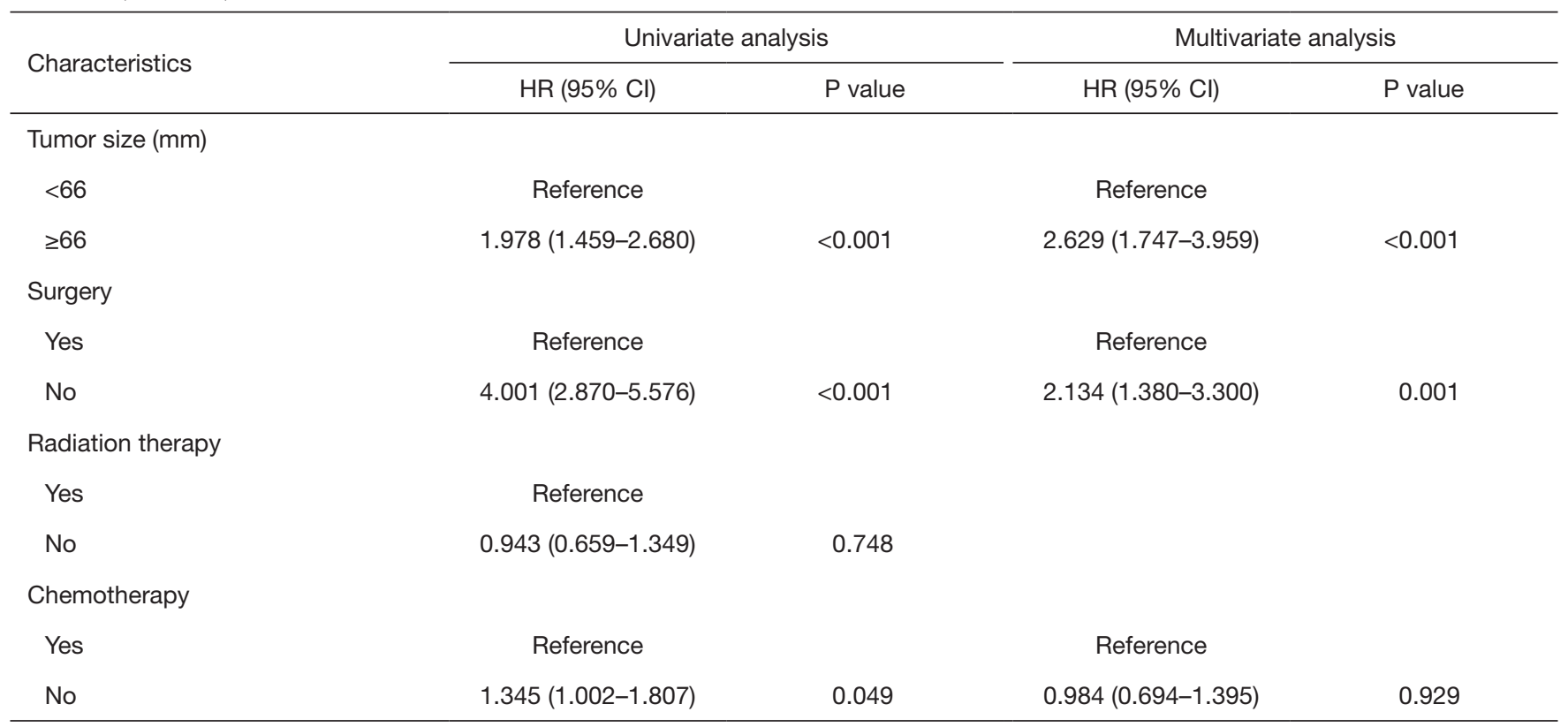

OS, overall survival; MFH-B, malignant fibrous histiocytoma of bone; HR, hazard ratio; Cl, confidence interval.

Table 3 Univariate and multivariate analyses of CSS in patients with MFH-B

\begin{tabular}{|c|c|c|c|c|}
\hline Characteristics & \multicolumn{2}{|c|}{ Univariate analysis } & \multicolumn{2}{|c|}{ Multivariate analysis } \\
\hline \multicolumn{5}{|l|}{ Race } \\
\hline White & Reference & & & \\
\hline Other & $1.554(0.787-3.072)$ & 0.204 & & \\
\hline \multicolumn{5}{|l|}{ Sex } \\
\hline Male & Reference & & & \\
\hline Female & $0.868(0.618-1.218)$ & 0.412 & & \\
\hline \multicolumn{5}{|c|}{ Age at diagnosis (years) } \\
\hline \multicolumn{5}{|c|}{ Year of diagnosis } \\
\hline 1970s & Reference & & Reference & \\
\hline $1980 \mathrm{~s}$ & $0.506(0.263-0.976)$ & 0.042 & $1.549(0.669-3.584)$ & 0.307 \\
\hline 1990s & $0.546(0.281-1.059)$ & 0.073 & $1.752(0.714-4.300)$ & 0.221 \\
\hline $2000 s$ & $0.367(0.192-0.701)$ & 0.002 & $0.890(0.381-2.080)$ & 0.789 \\
\hline 2010s & $0.394(0.173-0.897)$ & 0.026 & 1.195 (0.442-3.233) & 0.726 \\
\hline
\end{tabular}

Table 3 (Continued) 
Table 3 (Continued)

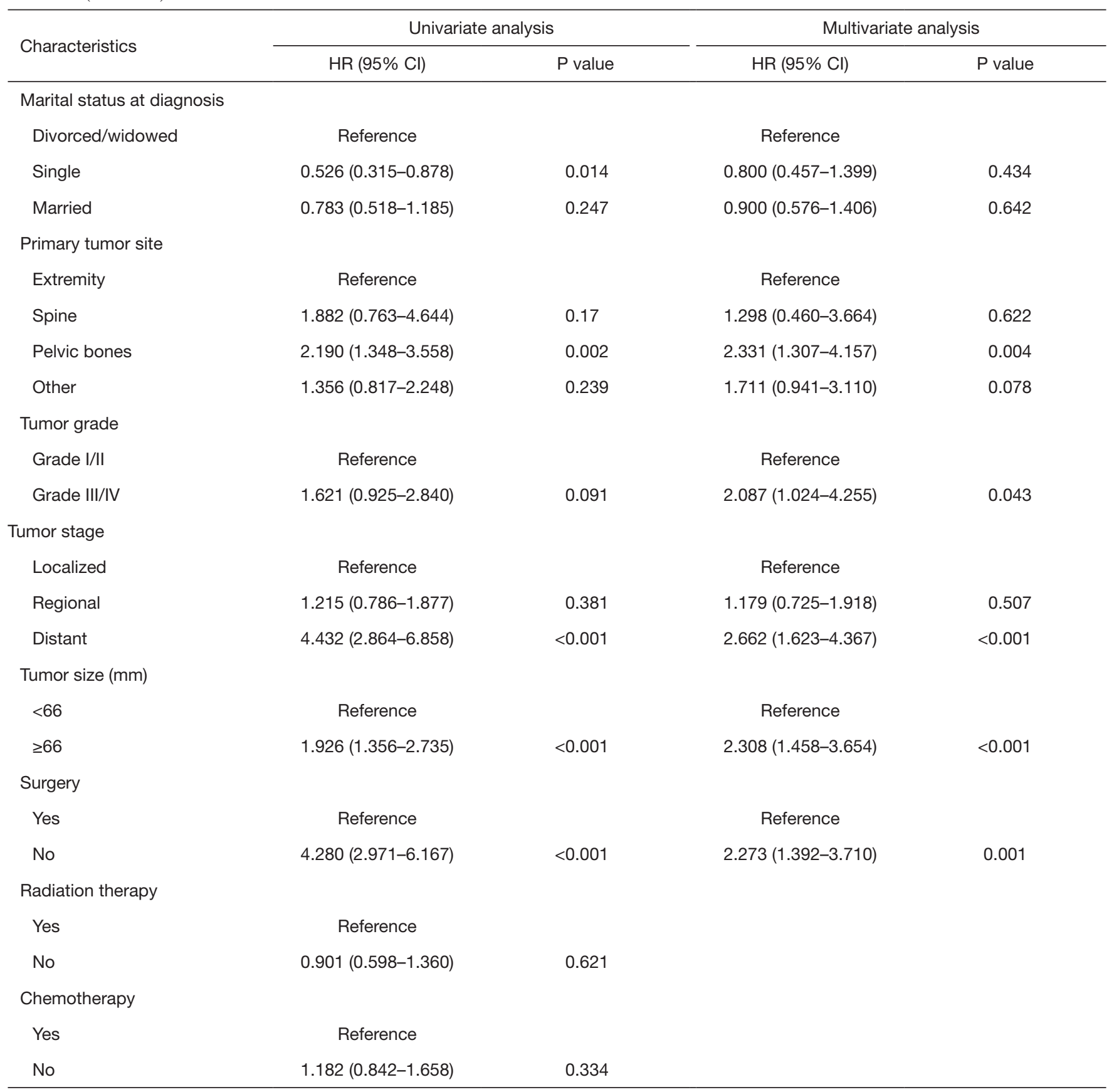

CSS, cancer-specific survival; MFH-B, malignant fibrous histiocytoma of bone; HR, hazard ratio; Cl, confidence interval.

MFH-B before and after 2000 were significantly different during the long time period (Figure S4). Most independent prognostic factors of OS and CSS were consistent during the long-time span while some changed after 2000 (Tables S1-S4).

\section{Development and validation of the nomograms}

Nomograms integrating statistically significant prognostic variables of OS and CSS were established (Figure 3). Each prognostic factor including age at diagnosis, tumor site, 

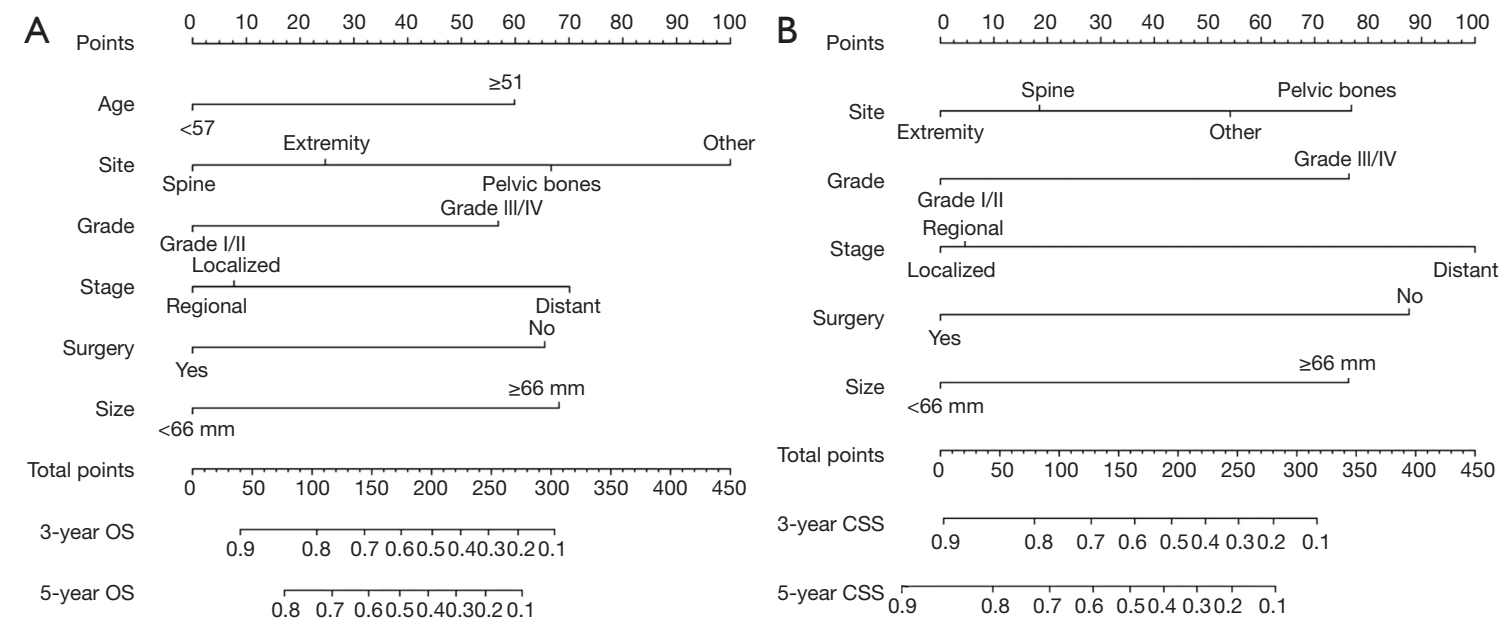

Figure 3 Nomograms predicting 3- and 5-year OS (A) and 3- and 5-year CSS (B) of patients with MFH-B. Prognostic factors including age at diagnosis, tumor site, tumor grade, tumor stage, tumor size and surgical treatment had corresponding scores in nomograms. The 3- and 5 -year OS rate and CSS rate could be predicted by adding up scores for each factor and connecting to specific survival rate based on the total scores. OS, overall survival; CSS, cancer-specific survival.

Table 4 Detailed scores of prognostic factors in the nomograms

\begin{tabular}{|c|c|c|}
\hline Characteristics & $\begin{array}{c}\text { The nomogram } \\
\text { of OS }\end{array}$ & $\begin{array}{c}\text { The nomogram of } \\
\text { CSS }\end{array}$ \\
\hline \multicolumn{3}{|c|}{ Age at diagnosis (years) } \\
\hline$<57$ & 0 & - \\
\hline$\geq 57$ & 60 & - \\
\hline \multicolumn{3}{|c|}{ Primary tumor site } \\
\hline Extremity & 25 & 0 \\
\hline Spine & 0 & 19 \\
\hline Pelvic bones & 67 & 77 \\
\hline Other & 100 & 54 \\
\hline \multicolumn{3}{|l|}{ Tumor grade } \\
\hline Grade I/II & 0 & 0 \\
\hline Grade III/IV & 57 & 76 \\
\hline \multicolumn{3}{|l|}{ Tumor stage } \\
\hline Localized & 8 & 0 \\
\hline Regional & 0 & 5 \\
\hline Distant & 70 & 100 \\
\hline \multicolumn{3}{|l|}{ Tumor size (mm) } \\
\hline$<66$ & 0 & 0 \\
\hline$\geq 66$ & 68 & 76 \\
\hline \multicolumn{3}{|l|}{ Surgery } \\
\hline Yes & 0 & 0 \\
\hline No & 65 & 88 \\
\hline
\end{tabular}

OS, overall survival; CSS, cancer-specific survival. grade, stage, size and surgery had a corresponding score in nomograms (Table 4). The 3- and 5-year OS rate and CSS rate could be predicted by adding up scores for each factor and connecting to specific survival rate based on the total scores.

The internal validation of nomograms was tested by the discrimination and calibration. The C-index for OS and CSS in the internal validation were 0.74 (95\% CI, $0.70-0.77$ ) and 0.74 (95\% CI, 0.70-0.78), accordingly. As illustrated in Figure 4, the ROC curves of nomograms demonstrated excellent discrimination for the prediction of survival rate, and the area under the curve (AUC) of nomograms for 3-year OS, 5-year OS, 3-year CSS and 5 -year CSS were $0.803,0.810,0.794$ and 0.812 , respectively. Calibration plots suggested optimal concordance between the predictive outcomes of nomograms with the actual survival (Figure 4).

Overall, we established and validated the nomograms to predict precise survival rate of patients with MFH-B. With these nomograms, the prognostic factors of $\mathrm{MFH}-\mathrm{B}$ could be identified and the precise rate of survival could be calculated according to the total scores. Take one patient for example, the 60-year-old patient was diagnosed with MFH-B, and the tumor was located in the upper limb with the primary tumor size of $8 \mathrm{~cm}$. Then the surgical treatment was given to him and the tumor was found to be localized and undifferentiated (Grade III/IV). Therefore, 

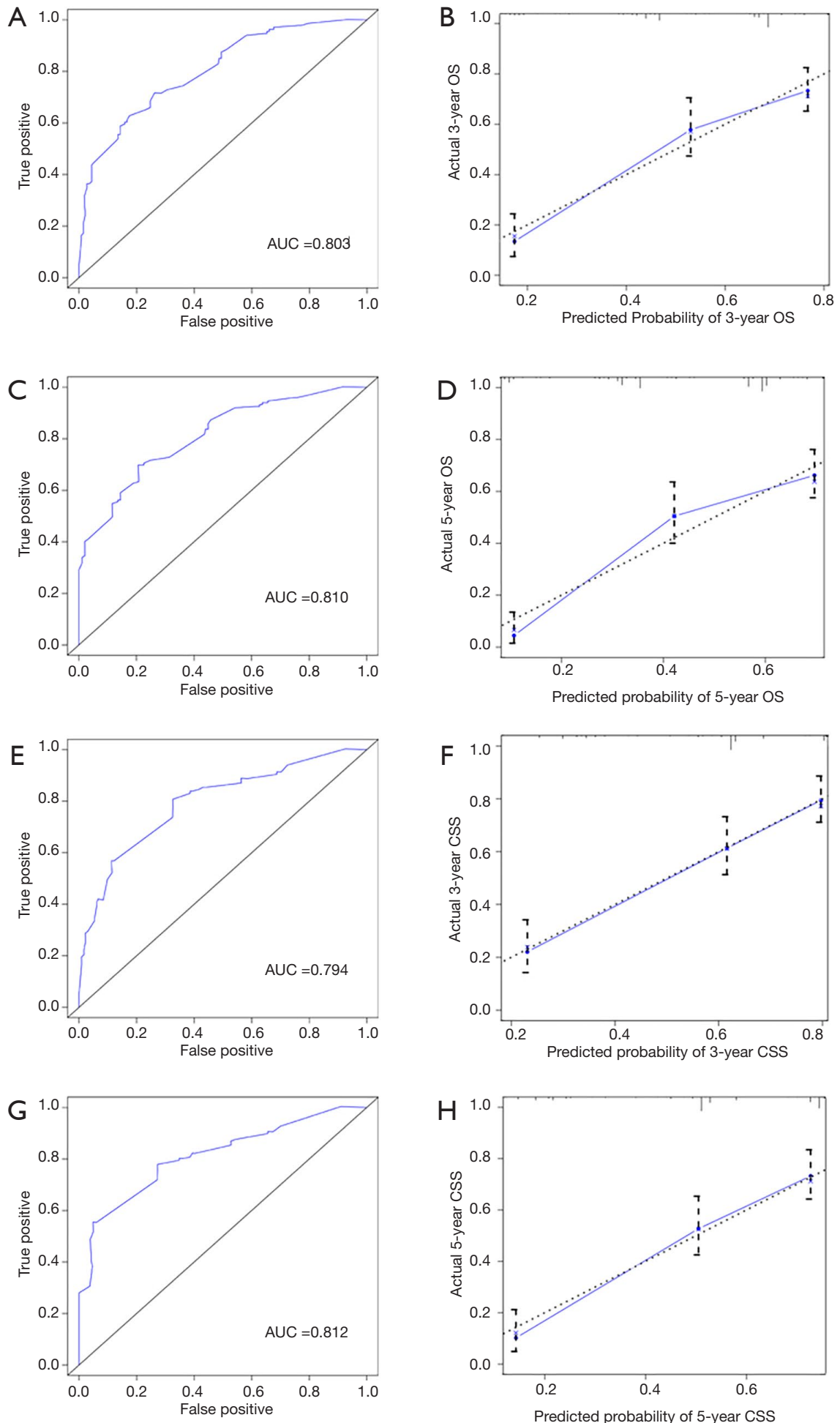

Figure 4 Internal validation of nomograms to predict OS and CSS. Discrimination: the AUC of the nomograms for 3-year OS (A), 5-year OS (C), 3-year CSS (E) and 5-year CSS (G) were 0.803, 0.810, 0.794 and 0.812, accordingly. Calibration: the calibration plots of the nomograms for 3-year OS (B), 5-year OS (D), 3-year CSS (F) and 5-year CSS (H). OS, overall survival; CSS, cancer-specific survival; AUC, areas under the curve. 
the estimated rates of 3 - and 5 -year OS were $43 \%$ and $31 \%$ accordingly. The rate of 3- and 5-year CSS could also be estimated in the same way.

\section{Discussion}

MFH-B is an extremely rare and aggressive bone tumor. Patients with MFH-B could easily end up with poor prognosis due to low incidence and relatively high malignancy of this tumor $(2,18,19)$. Relevant studies on MFH-B were limited by the amount of samples, and recent studies focused on the radiographic aspects of MFH-B while clinical studies on prognosis haven't been updated in the past few decades (20). Given the poor prognosis of MFH-B. It is extremely necessary to analyze related prognostic factors and then conduct personalized assessment and treatment. Several prognostic variables including age, tumor stage, tumor size, the depth of tumor, surgical treatment, chemotherapy and surgical margin were reported to correlate with the prognosis of MFH-B (6-8,18,21). But in terms of the predictive prognosis of malignant tumor, single prognostic factor may be insufficient to reach valid conclusion. The nomograms, which integrated statistically significant prognostic variables, were effective in the prediction of survival in individual patient $(22,23)$. Until now, there is no nomogram predicting the OS and CSS of MFH-B. In this study, the SEER database was utilized to include national-level data of MFH-B, so as to enlarge the valid sample size. Nomograms were constructed which have the ability of predicting 3- and 5-year OS and CSS of MFH-B.

Through univariate and multivariate analysis, several independent prognostic factors including age at diagnosis, tumor site, grade, stage, size and surgery were identified. Our study was in consistent with the previous studies which demonstrated that tumor stage was one important prognostic factor (21). As is defined in SEER database, the localized MFH-B was confined to cortex of bone, while the regional tumors extended beyond the cortex of bone and distant tumors migrated from the primary sites to other parts of the body (16). Infiltrating growth was one major feature of pathology of MFH-B (18). Therefore, the localized MFH-B was in the relatively early stage of the disease and the effect of treatment would be better. Our study also revealed for the first time that larger tumor size $(>66 \mathrm{~mm}$ ) significantly correlated with poorer prognosis for OS and CSS. It was reported that tumor size was the independent prognostic factor for prognosis of several solid tumors, as well as in some bone tumors (24-26). MFH-B with large size may be associated with late stage of tumor and metastasis, thus leading to poorer prognosis. For MFH-B in the spine and pelvic bones, it is much more difficult to achieve safe surgical margins compared with that in the extremity. Although in this study, it seems there was no significant survival different between MFH-B in the spine and extremity. The reason may lie in the extremely low incidence of this bone tumor and small sample size of $\mathrm{MFH}-\mathrm{B}$ in the spine. Marital status is an important social characteristic which reflects the social support of patients. OS was reported to be worse in single patients with soft tissue sarcoma while the role of marital status in MFH-B still needs further study (27).

The multidisciplinary treatment for MFH-B is composed of surgery, chemotherapy and radiation therapy in some cases $(6,28)$. In our study, surgical treatment was identified to be statistically significant via multivariate analyses. Surgery has been applied as the major treatment for MFH-B for several decades, which was reported to be effective to improve the prognosis $(6,29)$. Natarajan et al. specially reported that compared with resection alone, limb salvage surgery with customized mega prostheses for MFH-B may improve the prognosis and quality of life (30). Currently, neoadjuvant chemotherapy with surgical treatment has been recommended as the standardized treatment for patients with MFH-B (31). As is reported, neoadjuvant chemotherapy improved the survival rate of MFH-B significantly $(8,31)$, although some studies demonstrated that MFH-B had low chemosensitivity and neoadjuvant chemotherapy didn't effect prognosis $(32,33)$. The current study suggested that there seemed no significant correlation between survival rates and chemotherapy. In our view, this was partly because the limited number of sample size and the long period of follow-up time during which the standard treatment kept changing. Besides, the detailed chemotherapy protocol was unavailable in the SEER database, which limited the further analysis based on the subgroup of chemotherapy protocol. Radiotherapy has been under controversy in terms of treatment for MFH-B, and we couldn't reach a conclusion that radiotherapy improved prognosis of MFH-B significantly in the current study $(2,29)$. Previous studies demonstrated that MFH-B and osteosarcoma shared some similarities in histologic and clinical characteristics $(29,34)$. Radiotherapy was not included in the standard treatment for osteosarcoma due to its radioresistant, therefore radiation for MFH-B may not prolong the survival of patients either. Some independent 
risk factors changed after 2000, and part of the reasons may lie in the improved treatment protocols in recent years. The long-time span study and its retrospective nature might lead to some inevitable bias while the main aim of study was to present characteristics and survival of this extremely rare bone tumor. Besides, we also include the year of diagnosis into the multivariate Cox regression analysis to attenuate these kinds of bias.

On the basis of significant prognostic variables via multivariate analyses, we constructed the nomograms of MFH-B. To our knowledge, no other nomograms predicting MFH-B exists at present, and doctors could easily predict precise survival rate of patients with MFH-B via these visible tools. The nomograms were assessed by ROC curves and C-index, which suggested good internal validation. Calibration plots also revealed optimal concordance between the predictive outcomes of nomograms with the actual survival.

As far as is known, this is the first sizeable study that identifies independent prognostic factors of MFH-B and constructs predictive nomograms based on relatively large sample size compared with previous studies, in which the largest sample size was 81 (29). The 42-year time was divided into 5 parts to present the frequency of MFH-B in each decade. The specific data of SEER historic stage in 28 patients was missing in the database, which was supplemented by MICE. In spite of the predictive ability of nomograms in the current study, there are some potential limitations that need to be taken into consideration. Firstly, because the nomograms were established on the basis of retrospective data from the SEER database, errors and bias of some cases inevitably occurred. Secondly, detailed information of treatment including surgical margin, and location of the metastases, radiation dosage and chemotherapy protocols were unavailable in the SEER database, which limited further analysis based on the subgroup of treatment and may undermine the effectiveness of nomograms. It is noted that this limitation also occurred in some high-quality clinical studies, in which part of information about surgery and chemotherapy were incomplete $(35,36)$. Thirdly, the sample sizes were still relatively small because of the extremely low incidence of MFH-B although the data were retrieved from the national-level database, thus leading to the missing of some significant prognostic factors. Besides, the C-index for OS and CSS represents relatively good predictive ability, but still not very ideal. Part of the reasons may lie in the relatively small sample size and limited number of prognostic factors which could be further included in Cox proportional hazards model. Finally, there was no external validation in our study due to limited number of included sample size $(\mathrm{N}=250)$. The constructed models need to be further assessed by external validation.

\section{Conclusions}

In summary, the current study presented clinical characteristics and identified that age $\geq 57$ years, pelvic bones and other tumor sites, Grade III/IV, distant tumor stage, tumor size $\geq 66 \mathrm{~mm}$ and no surgery were associated with poorer prognosis of MFH-B. Nomograms predicting 3- and 5-year OS and CSS were established and internally validated. Based on nomograms, individual survival rate could be estimated and doctors could identify mortality risk.

\section{Acknowledgments}

Funding: This study was sponsored by the National Natural Science Foundation of China (NSFC; No. 81902745), Hunan Provincial Research and Development Program in Key Areas (2019WK2071), Natural Science Foundation of Hunan Province (No. 2018JJ3716), Key Research and Development Program of Hunan Province Science and Technology Department (No. 2017DK2013), Scholar Support Funding from the Hunan Association for Science and Technology (No. 2017TJ-Q19) and the Hunan Provincial financial department program [No.(2018)95].

\section{Footnote}

Conflicts of Interest: All authors have completed the ICMJE uniform disclosure form (available at http://dx.doi. org/10.21037/tcr.2020.01.56). The authors have no conflicts of interest to declare.

Etbical Statement: The authors are accountable for all aspects of the work in ensuring that questions related to the accuracy or integrity of any part of the work are appropriately investigated and resolved. The study was conducted in accordance with the Declaration of Helsinki (as revised in 2013). The collection of data could be carried out without informed consent of patients, as there was no identifying information of individual patient in the SEER database. The research data was accessed with the permission of the National Cancer Institute (Username: 11020-Nov2018). 
Open Access Statement: This is an Open Access article distributed in accordance with the Creative Commons Attribution-NonCommercial-NoDerivs 4.0 International License (CC BY-NC-ND 4.0), which permits the noncommercial replication and distribution of the article with the strict proviso that no changes or edits are made and the original work is properly cited (including links to both the formal publication through the relevant DOI and the license). See: https://creativecommons.org/licenses/by-nc-nd/4.0/.

\section{References}

1. Feldman F, Norman D. Intra- and extraosseous malignant histiocytoma (malignant fibrous xanthoma). Radiology 1972;104:497-508.

2. Capanna R, Bertoni F, Bacchini P, et al. Malignant fibrous histiocytoma of bone. The experience at the Rizzoli Institute: report of 90 cases. Cancer 1984;54:177-87.

3. Link TM, Haeussler MD, Poppek S, et al. Malignant fibrous histiocytoma of bone: conventional X-ray and MR imaging features. Skeletal Radiol 1998;27:552-8.

4. Papagelopoulos PJ, Galanis EC, Sim FH, et al. Clinicopathologic features, diagnosis, and treatment of malignant fibrous histiocytoma of bone. Orthopedics 2000;23:59-65; quiz 66-7.

5. Dunham WK, Wilborn WH. Malignant fibrous histiocytoma of bone. Report of two cases and review of the literature. J Bone Joint Surg Am 1979;61:939-42.

6. Bielack SS, Schroeders A, Fuchs N, et al. Malignant fibrous histiocytoma of bone: a retrospective EMSOS study of 125 cases. European Musculo-Skeletal Oncology Society. Acta Orthop Scand 1999;70:353-60.

7. Belal A, Kandil A, Allam A, et al. Malignant fibrous histiocytoma: a retrospective study of 109 cases. Am J Clin Oncol 2002;25:16-22.

8. Ham SJ, Hoekstra HJ, van der Graaf WT, et al. The value of high-dose methotrexate-based neoadjuvant chemotherapy in malignant fibrous histiocytoma of bone. J Clin Oncol 1996;14:490-6.

9. Bacci G, Picci P, Mercuri M, et al. Neoadjuvant chemotherapy for high grade malignant fibrous histiocytoma of bone. Clin Orthop Relat Res 1998;(346):178-89.

10. Ganne-Carrié N, Layese R, Bourcier V, et al. Nomogram for individualized prediction of hepatocellular carcinoma occurrence in hepatitis $\mathrm{C}$ virus cirrhosis (ANRS CO12 CirVir). Hepatology 2016;64:1136-47.

11. Huang YQ, Liang CH, He L, et al. Development and validation of a radiomics nomogram for preoperative prediction of lymph node metastasis in colorectal cancer. J Clin Oncol 2016;34:2157-64.

12. Surveillance, Epidemiology, and End Results (SEER) Program (www.seer.cancer.gov) SEER*Stat Database: Incidence - SEER 18 Regs Custom Data (with additional treatment fields), Nov 2018 Sub (1975-2016 varying) Linked To County Attributes - Total U.S., 1969-2017 Counties, National Cancer Institute, DCCPS, Surveillance Research Program, released April 2019, based on the November 2018 submission.

13. Stuart EA, Azur M, Frangakis C, et al. Multiple imputation with large data sets: a case study of the Children's Mental Health Initiative. Am J Epidemiol 2009;169:1133-9.

14. Rubin DB. Multiple imputation for nonresponse in surveys. Hoboken: John Wiley \& Sons, 2004.

15. Camp RL, Dolled-Filhart M, Rimm DL. X-tile: a new bio-informatics tool for biomarker assessment and outcome-based cut-point optimization. Clin Cancer Res 2004;10:7252-9.

16. Ruhl JL CC, Hurlbut, A, Ries LAG, et al. Summary stage 2018: codes and coding instructions. Bethesda: National Cancer Institute, 2018.

17. Uno H, Cai T, Pencina MJ, et al. On the C-statistics for evaluating overall adequacy of risk prediction procedures with censored survival data. Stat Med 2011;30:1105-17.

18. Huvos AG, Heilweil M, Bretsky SS. The pathology of malignant fibrous histiocytoma of bone. A study of 130 patients. Am J Surg Pathol 1985;9:853-71.

19. Tarkkanen M, Larramendy ML, Böhling T, et al. Malignant fibrous histiocytoma of bone: analysis of genomic imbalances by comparative genomic hybridisation and C-MYC expression by immunohistochemistry. Eur J Cancer 2006;42:1172-80.

20. Koplas MC, Lefkowitz RA, Bauer TW, et al. Imaging findings, prevalence and outcome of de novo and secondary malignant fibrous histiocytoma of bone. Skeletal Radiol 2010;39:791-8.

21. Kearney MM, Soule EH, Ivins JC. Malignant fibrous histiocytoma: a retrospective study of 167 cases. Cancer 1980;45:167-78.

22. Callegaro D, Miceli R, Bonvalot S, et al. Development and external validation of two nomograms to predict overall survival and occurrence of distant metastases in adults after surgical resection of localised soft-tissue sarcomas of the extremities: a retrospective analysis. Lancet Oncol 2016;17:671-80.

23. Rose PG, Java J, Whitney CW, et al. Nomograms 
predicting progression-free survival, overall survival, and pelvic recurrence in locally advanced cervical cancer developed from an analysis of identifiable prognostic factors in patients from nrg oncology/gynecologic oncology group randomized trials of chemoradiotherapy. J Clin Oncol 2015;33:2136-42.

24. Brookman-May SD, May M, Wolff I, et al. Evaluation of the prognostic significance of perirenal fat invasion and tumor size in patients with pT1-pT3a localized renal cell carcinoma in a comprehensive multicenter study of the CORONA project. Can we improve prognostic discrimination for patients with stage pT3a tumors? Eur Urol 2015;67:943-51.

25. Ost D, Goldberg J, Rolnitzky L, et al. Survival after surgery in stage IA and IB non-small cell lung cancer. Am J Respir Crit Care Med 2008;177:516-23.

26. Petrilli AS, de Camargo B, Filho VO, et al. Results of the Brazilian Osteosarcoma Treatment Group Studies III and IV: prognostic factors and impact on survival. J Clin Oncol 2006;24:1161-8.

27. Alamanda VK, Song Y, Holt GE. Effect of marital status on treatment and survival of extremity soft tissue sarcoma. Ann Oncol 2014;25:725-9.

28. Hristov B, Shokek O, Frassica DA. The role of radiation treatment in the contemporary management of bone tumors. J Natl Compr Canc Netw 2007;5:456-66.

29. Nishida J, Sim FH, Wenger DE, et al. Malignant fibrous histiocytoma of bone. A clinicopathologic study of 81

Cite this article as: Qi L, Tu C, Ren X, Chen R, Wan L, Zhang C, Li Z. Clinical characteristics and prognostic factors of malignant fibrous histiocytoma of bone: a SEER populationbased study. Transl Cancer Res 2020;9(3):1604-1617. doi: 10.21037/tcr.2020.01.56 patients. Cancer 1997;79:482-93.

30. Natarajan MV, Mohanlal P, Bose JC. Limb salvage surgery complimented by customised mega prostheses for malignant fibrous histiocytomas of bone. J Orthop Surg (Hong Kong) 2007;15:352-6.

31. Hugate RR, Wilkins RM, Kelly CM, et al. Intraarterial chemotherapy for extremity osteosarcoma and $\mathrm{MFH}$ in adults. Clin Orthop Relat Res 2008;466:1292-301.

32. Little DG, McCarthy SW. Malignant fibrous histiocytoma of bone: the experience of the New South Wales Bone Tumour Registry. Aust N Z J Surg 1993;63:346-51.

33. Picci P, Bacci G, Ferrari S, et al. Neoadjuvant chemotherapy in malignant fibrous histiocytoma of bone and in osteosarcoma located in the extremities: analogies and differences between the two tumors. Ann Oncol 1997;8:1107-15.

34. Jeon DG, Song WS, Kong CB, et al. MFH of bone and osteosarcoma show similar survival and chemosensitivity. Clin Orthop Relat Res 2011;469:584-90.

35. Song K, Song J, Chen F, et al. Does resection of the primary tumor improve survival in patients with metastatic chondrosarcoma? Clin Orthop Relat Res 2019;477:573-83.

36. Seisen T, Jamzadeh A, Leow JJ, et al. Adjuvant chemotherapy vs observation for patients with adverse pathologic features at radical cystectomy previously treated with neoadjuvant chemotherapy. JAMA Oncol 2018;4:225-9. 

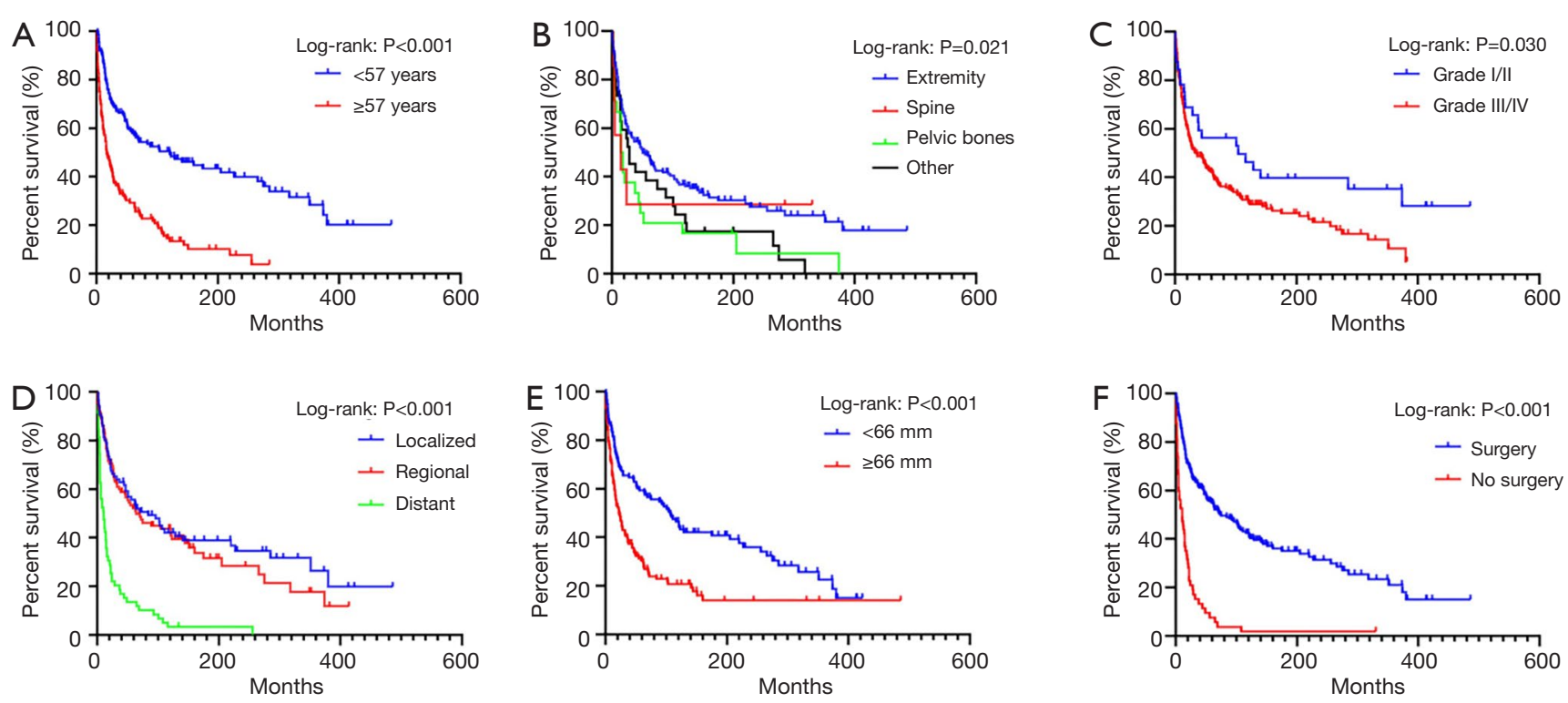

Figure S1 Kaplan-Meier curves of OS in different groups of age at diagnosis (A), tumor site (B), tumor grade (C), tumor stage (D), tumor size (E) and surgical treatment (F). OS, overall survival.
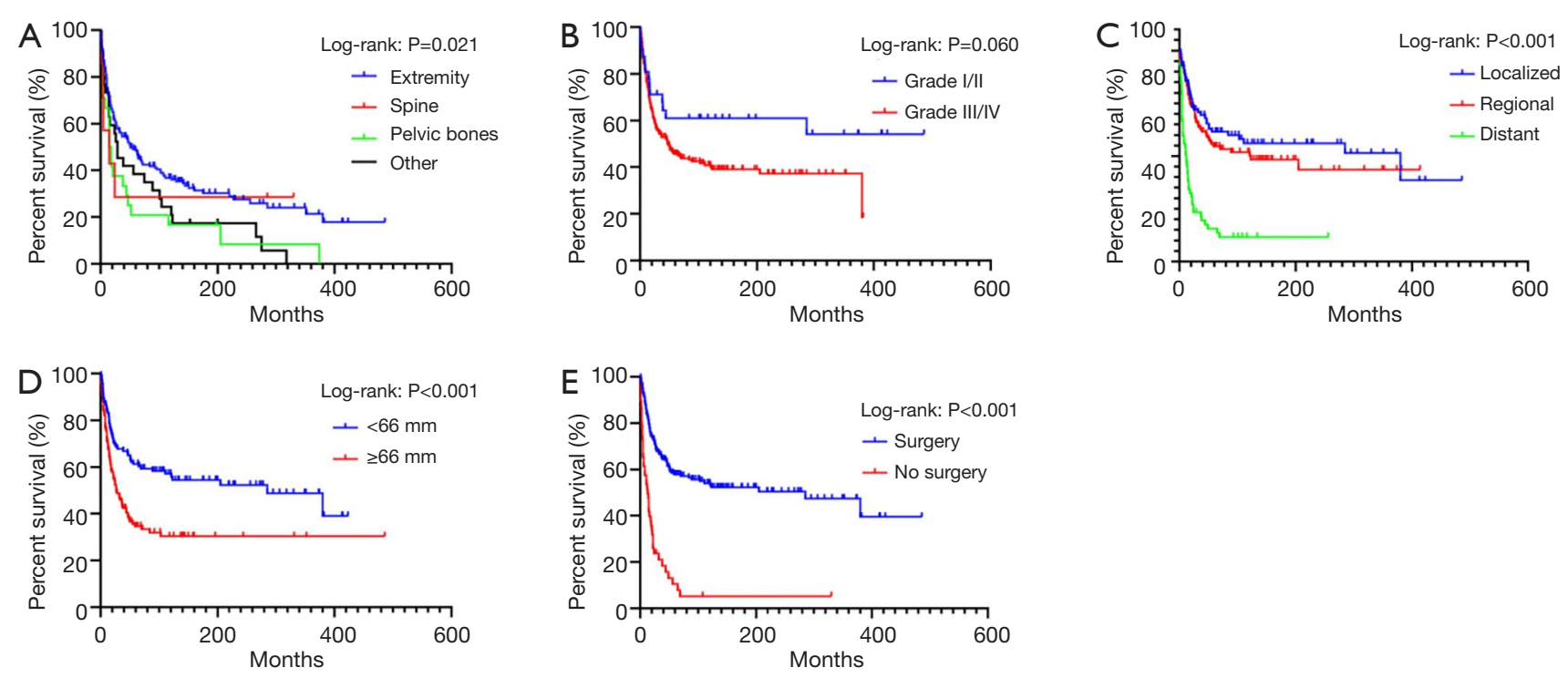

Figure S2 Kaplan-Meier curves of CSS in different groups of tumor site (A), tumor grade (B), tumor stage (C), tumor size (D) and surgical treatment (E). CSS, cancer-specific survival. 

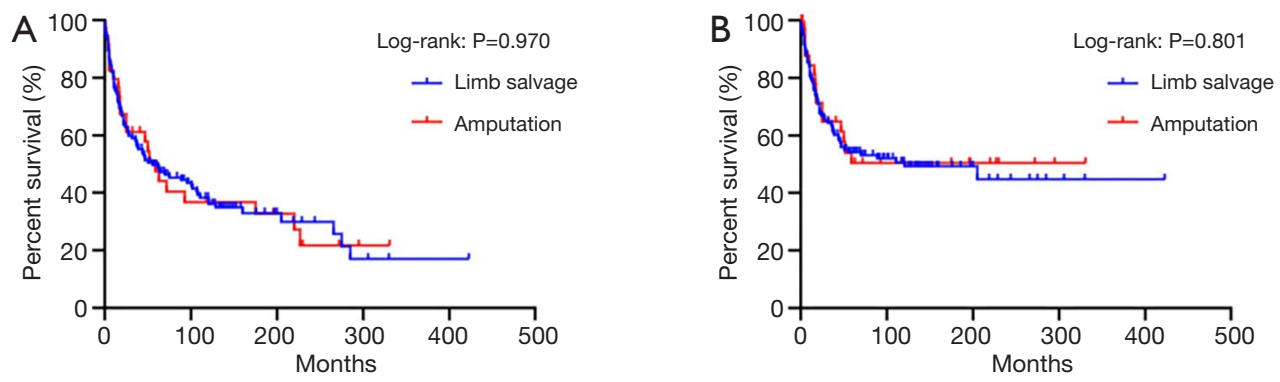

Figure S3 Kaplan-Meier curves of OS (A) and CSS (B) in patients treated with limb salvage and amputation. OS, overall survival; CSS, cancer-specific survival.
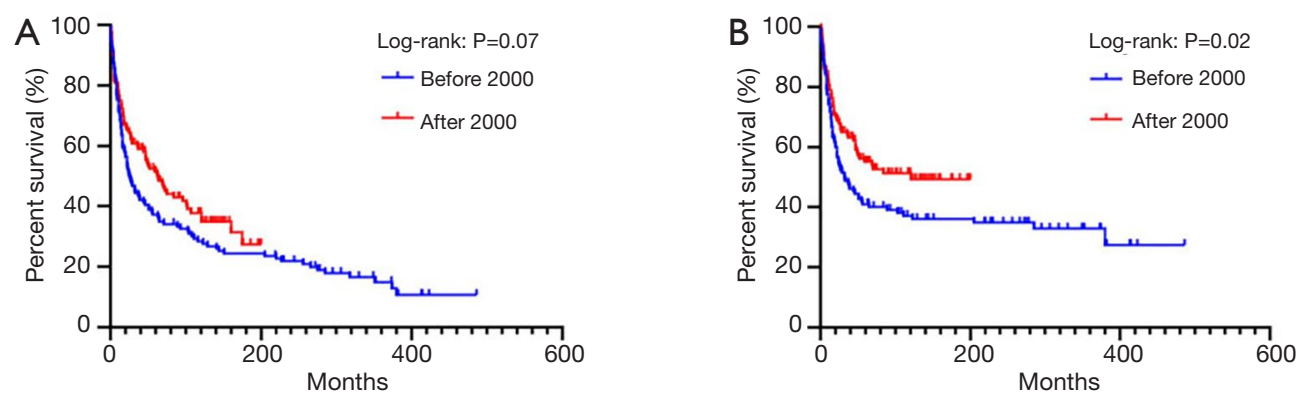

Figure S4 Kaplan-Meier curves of OS (A) and CSS (B) before and after 2000. OS, overall survival; CSS, cancer-specific survival. 
Table S1 Univariate and multivariate analyses of OS in patients with MFH-B before 2000

\begin{tabular}{|c|c|c|c|c|}
\hline \multirow{2}{*}{ Characteristics } & \multicolumn{2}{|c|}{ Univariate analysis } & \multicolumn{2}{|c|}{ Multivariate analysis } \\
\hline & $\mathrm{HR}(95 \% \mathrm{Cl})$ & $P$ value & HR $(95 \% \mathrm{Cl})$ & $P$ value \\
\hline \multicolumn{5}{|l|}{ Race } \\
\hline White & Reference & & & \\
\hline Other & $1.895(0.764-4.700)$ & 0.168 & & \\
\hline Black & $0.887(0.447-1.762)$ & 0.733 & & \\
\hline \multicolumn{5}{|l|}{ Sex } \\
\hline Male & Reference & & & \\
\hline Female & $1.106(0.758-1.616)$ & 0.601 & & \\
\hline \multicolumn{5}{|c|}{ Age at diagnosis (years) } \\
\hline$<57$ & Reference & & Reference & \\
\hline$\geq 57$ & $3.222(2.135-4.862)$ & $<0.001$ & 2.057 (1.272-3.329) & 0.003 \\
\hline \multicolumn{5}{|l|}{ Year of diagnosis } \\
\hline 1970 s & Reference & & Reference & \\
\hline $1980 s$ & $0.536(0.294-0.977)$ & 0.042 & $1.675(0.738-3.798)$ & 0.217 \\
\hline $1990 s$ & $0.614(0.335-1.126)$ & 0.115 & $2.553(1.059-6.158)$ & 0.037 \\
\hline \multicolumn{5}{|c|}{ Marital status at diagnosis } \\
\hline Divorced/widowed & Reference & & Reference & \\
\hline Single & $0.374(0.202-0.693)$ & 0.002 & $0.594(0.302-1.169)$ & 0.131 \\
\hline Married & $0.633(0.407-0.986)$ & 0.043 & $1.033(0.634-1.684)$ & 0.89 \\
\hline \multicolumn{5}{|l|}{ Primary tumor site } \\
\hline Extremity & Reference & & Reference & \\
\hline Spine & $0.910(0.332-2.497)$ & 0.855 & $0.825(0.275-2.479)$ & 0.732 \\
\hline Pelvic bones & $1.518(0.803-2.867)$ & 0.199 & $1.545(0.684-3.683)$ & 0.326 \\
\hline Other & 1.597 (0.988-2.538) & 0.056 & 3.177 (1.662-6.071) & $<0.001$ \\
\hline \multicolumn{5}{|l|}{ Tumor grade } \\
\hline Grade I/II & Reference & & Reference & \\
\hline Grade III/IV & $1.858(1.109-3.114)$ & 0.019 & 1.429 (0.710-2.878) & 0.318 \\
\hline \multicolumn{5}{|l|}{ Tumor stage } \\
\hline Localized & Reference & & Reference & \\
\hline Regional & 1.509 (0.956-2.382) & 0.077 & 1.007 (0.587-1.727) & 0.980 \\
\hline Distant & $3.750(2.314-6.076)$ & $<0.001$ & 1.740 (1.001-3.028) & 0.050 \\
\hline \multicolumn{5}{|l|}{ Tumor size (mm) } \\
\hline$<66$ & Reference & & Reference & \\
\hline$\geq 66$ & $2.61(1.762-3.866)$ & $<0.001$ & $4.114(2.303-7.348)$ & $<0.001$ \\
\hline \multicolumn{5}{|l|}{ Surgery } \\
\hline Yes & Reference & & Reference & \\
\hline No & 3.325 (2.190-5.049) & $<0.001$ & 2.178 (1.265-3.750) & 0.005 \\
\hline \multicolumn{5}{|l|}{ Radiation therapy } \\
\hline Yes & Reference & & & \\
\hline No & $0.960(0.614-1.502)$ & 0.859 & & \\
\hline \multicolumn{5}{|l|}{ Chemotherapy } \\
\hline Yes & Reference & & & \\
\hline No & 1.119 (0.755-1.657) & 0.576 & & \\
\hline
\end{tabular}

OS, overall survival; MFH-B, malignant fibrous histiocytoma of bone; $\mathrm{HR}$, hazard ratio; $\mathrm{Cl}$, confidence interval. 
Table S2 Univariate and multivariate analyses of OS in patients with MFH-B after 2000

\begin{tabular}{|c|c|c|c|c|}
\hline \multirow{2}{*}{ Characteristics } & \multicolumn{2}{|c|}{ Univariate analysis } & \multicolumn{2}{|c|}{ Multivariate analysis } \\
\hline & $\mathrm{HR}(95 \% \mathrm{Cl})$ & $P$ value & $\mathrm{HR}(95 \% \mathrm{Cl})$ & $P$ value \\
\hline \multicolumn{5}{|l|}{ Race } \\
\hline White & Reference & & & \\
\hline Other & 1.527 (0.656-3.555) & 0.327 & & \\
\hline Black & $1.171(0.580-2.368)$ & 0.659 & & \\
\hline \multicolumn{5}{|l|}{ Sex } \\
\hline Male & Reference & & & \\
\hline Female & $0.835(0.525-1.328)$ & 0.446 & & \\
\hline \multicolumn{5}{|c|}{ Age at diagnosis (years) } \\
\hline$<57$ & Reference & & Reference & \\
\hline$\geq 57$ & $2.161(1.351-3.456)$ & 0.001 & $1.664(0.988-2.803)$ & 0.056 \\
\hline \multicolumn{5}{|l|}{ Year of diagnosis } \\
\hline $2000 s$ & Reference & & Reference & \\
\hline $2010 s$ & $1.218(0.667-2.225)$ & 0.521 & $1.509(0.794-2.869)$ & 0.209 \\
\hline \multicolumn{5}{|c|}{ Marital status at diagnosis } \\
\hline Divorced/widowed & Reference & & & \\
\hline Single & $0.925(0.443-1.932)$ & 0.836 & & \\
\hline Married & $1.334(0.685-2.595)$ & 0.397 & & \\
\hline \multicolumn{5}{|l|}{ Primary tumor site } \\
\hline Extremity & Reference & & Reference & \\
\hline Spine & $5.895(0.788-44.073)$ & 0.084 & $4.134(0.468-36.485)$ & 0.201 \\
\hline Pelvic bones & 2.169 (1.129-4.167) & 0.02 & 1.957 (0.967-3.959) & 0.062 \\
\hline Other & $1.104(0.474-2.569)$ & 0.818 & 1.645 (0.545-4.970) & 0.377 \\
\hline \multicolumn{5}{|l|}{ Tumor grade } \\
\hline Grade I/II & Reference & & Reference & \\
\hline Grade III/IV & $1.361(0.494-3.752)$ & 0.552 & 2.491 (0.678-9.143) & 0.169 \\
\hline \multicolumn{5}{|l|}{ Tumor stage } \\
\hline Localized & Reference & & Reference & \\
\hline Regional & $0.867(0.479-1.570)$ & 0.638 & $0.866(0.460-1.633)$ & 0.657 \\
\hline Distant & $4.166(2.240-7.748)$ & $<0.001$ & 3.025 (1.366-6.697) & 0.006 \\
\hline \multicolumn{5}{|l|}{ Tumor size (mm) } \\
\hline$<66$ & Reference & & Reference & \\
\hline$\geq 66$ & $1.526(0.945-2.463)$ & 0.084 & $1.728(1.005-2.971)$ & 0.048 \\
\hline \multicolumn{5}{|l|}{ Surgery } \\
\hline Yes & Reference & & Reference & \\
\hline No & $5.070(2.877-8.935)$ & $<0.001$ & $1.907(0.851-4.274)$ & 0.117 \\
\hline \multicolumn{5}{|l|}{ Radiation therapy } \\
\hline Yes & Reference & & & \\
\hline No & $0.948(0.520-1.730)$ & 0.862 & & \\
\hline \multicolumn{5}{|l|}{ Chemotherapy } \\
\hline Yes & Reference & & & \\
\hline No & $1.556(0.975-2.481)$ & 0.064 & & \\
\hline
\end{tabular}

OS, overall survival; MFH-B, malignant fibrous histiocytoma of bone; HR, hazard ratio; $\mathrm{Cl}$, confidence interval. 
Table S3 Univariate and multivariate analyses of CSS in patients with MFH-B before 2000

\begin{tabular}{|c|c|c|c|c|}
\hline \multirow{2}{*}{ Characteristics } & \multicolumn{2}{|c|}{ Univariate analysis } & \multicolumn{2}{|c|}{ Multivariate analysis } \\
\hline & $\mathrm{HR}(95 \% \mathrm{Cl})$ & $P$ value & $\mathrm{HR}(95 \% \mathrm{Cl})$ & $P$ value \\
\hline \multicolumn{5}{|l|}{ Race } \\
\hline White & Reference & & & \\
\hline Other & $1.740(0.632-4.791)$ & 0.284 & & \\
\hline Black & $1.159(0.557-2.412)$ & 0.693 & & \\
\hline \multicolumn{5}{|l|}{ Sex } \\
\hline Male & Reference & & & \\
\hline Female & $0.862(0.557-1.334)$ & 0.505 & & \\
\hline \multicolumn{5}{|c|}{ Age at diagnosis (years) } \\
\hline$<57$ & Reference & & Reference & \\
\hline$\geq 57$ & $2.423(1.540-3.813)$ & $<0.001$ & $1.364(0.799-2.329)$ & 0.255 \\
\hline \multicolumn{5}{|l|}{ Year of diagnosis } \\
\hline 1970 s & Reference & & Reference & \\
\hline $1980 s$ & $0.516(0.267-0.996)$ & 0.049 & $1.453(0.568-3.716)$ & 0.436 \\
\hline $1990 s$ & $0.553(0.285-1.076)$ & 0.081 & $1.949(0.703-5.404)$ & 0.199 \\
\hline \multicolumn{5}{|c|}{ Marital status at diagnosis } \\
\hline Divorced/widowed & Reference & & Reference & \\
\hline Single & $0.448(0.231-0.870)$ & 0.018 & $0.691(0.330-1.450)$ & 0.329 \\
\hline Married & $0.563(0.342-0.928)$ & 0.024 & $0.794(0.454-1.387)$ & 0.418 \\
\hline \multicolumn{5}{|l|}{ Primary tumor site } \\
\hline Extremity & Reference & & Reference & \\
\hline Spine & $1.295(0.468-3.586)$ & 0.618 & $1.055(0.320-3.484)$ & 0.930 \\
\hline Pelvic bones & $1.641(0.808-3.332)$ & 0.171 & 1.836 (0.688-4.899) & 0.225 \\
\hline Other & $1.473(0.841-2.583)$ & 0.176 & $2.099(1.003-4.389)$ & 0.049 \\
\hline \multicolumn{5}{|l|}{ Tumor grade } \\
\hline Grade I/II & Reference & & Reference & \\
\hline Grade III/IV & $1.891(1.018-3.515)$ & 0.044 & $1.881(0.792-4.465)$ & 0.152 \\
\hline \multicolumn{5}{|l|}{ Tumor stage } \\
\hline Localized & Reference & & Reference & \\
\hline Regional & $1.652(0.963-2.835)$ & 0.068 & $1.380(0.742-2.567)$ & 0.309 \\
\hline Distant & 3.813 (2.202-6.603) & $<0.001$ & 1.963 (1.057-3.647) & 0.033 \\
\hline \multicolumn{5}{|l|}{ Tumor size (mm) } \\
\hline$<66$ & Reference & & Reference & \\
\hline$\geq 66$ & 2.619 (1.665-4.120) & $<0.001$ & $3.211(1.681-6.134)$ & $<0.001$ \\
\hline \multicolumn{5}{|l|}{ Surgery } \\
\hline Yes & Reference & & Reference & \\
\hline No & $3.471(2.195-5.491)$ & $<0.001$ & $2.389(1.300-4.392)$ & 0.005 \\
\hline \multicolumn{5}{|l|}{ Radiation therapy } \\
\hline Yes & Reference & & & \\
\hline No & $0.829(0.505-1.362)$ & 0.46 & & \\
\hline \multicolumn{5}{|l|}{ Chemotherapy } \\
\hline Yes & Reference & & & \\
\hline No & $1.027(0.656-1.606)$ & 0.907 & & \\
\hline
\end{tabular}

CSS, cancer-specific survival; MFH-B, malignant fibrous histiocytoma of bone; $\mathrm{HR}$, hazard ratio; $\mathrm{Cl}$, confidence interval. 
Table S4 Univariate and multivariate analyses of CSS in patients with MFH-B after 2000

\begin{tabular}{|c|c|c|c|c|}
\hline \multirow{2}{*}{ Characteristics } & \multicolumn{2}{|c|}{ Univariate analysis } & \multicolumn{2}{|c|}{ Multivariate analysis } \\
\hline & $\mathrm{HR}(95 \% \mathrm{Cl})$ & $P$ value & $\mathrm{HR}(95 \% \mathrm{Cl})$ & $P$ value \\
\hline \multicolumn{5}{|l|}{ Race } \\
\hline White & Reference & & & \\
\hline Other & $1.627(0.642-4.123)$ & 0.305 & & \\
\hline Black & $1.282(0.575-2.860)$ & 0.544 & & \\
\hline \multicolumn{5}{|l|}{ Sex } \\
\hline Male & Reference & & & \\
\hline Female & $0.890(0.518-1.526)$ & 0.671 & & \\
\hline \multicolumn{5}{|c|}{ Age at diagnosis (years) } \\
\hline$<57$ & Reference & & Reference & \\
\hline$\geq 57$ & $1.652(0.962-2.836)$ & 0.069 & $1.105(0.586-2.084)$ & 0.759 \\
\hline \multicolumn{5}{|l|}{ Year of diagnosis } \\
\hline $2000 s$ & Reference & & Reference & \\
\hline $2010 s$ & $1.109(0.566-2.173)$ & 0.763 & $1.435(0.699-2.948)$ & 0.325 \\
\hline \multicolumn{5}{|c|}{ Marital status at diagnosis } \\
\hline Divorced/widowed & Reference & & & \\
\hline Single & $0.835(0.346-2.016)$ & 0.689 & & \\
\hline Married & $1.431(0.659-3.106)$ & 0.365 & & \\
\hline \multicolumn{5}{|l|}{ Primary tumor site } \\
\hline Extremity & Reference & & Reference & \\
\hline Spine & $8.390(1.099-64.058)$ & 0.04 & $5.441(0.572-51.745)$ & 0.140 \\
\hline Pelvic bones & $2.973(1.514-5.835)$ & 0.002 & $2.697(1.282-5.674)$ & 0.009 \\
\hline Other & $0.541(0.131-2.242)$ & 0.397 & $0.600(0.096-3.770)$ & 0.586 \\
\hline \multicolumn{5}{|l|}{ Tumor grade } \\
\hline Grade I/II & Reference & & Reference & \\
\hline Grade III/IV & $1.794(0.436-7.376)$ & 0.418 & $1.714(0.280-10.482)$ & 0.560 \\
\hline \multicolumn{5}{|l|}{ Tumor stage } \\
\hline Localized & Reference & & Reference & \\
\hline Regional & $0.986(0.469-2.072)$ & 0.969 & $0.999(0.453-2.203)$ & 0.998 \\
\hline Distant & 5.609 (2.692-11.685) & $<0.001$ & $4.485(1.826-11.016)$ & 0.001 \\
\hline \multicolumn{5}{|l|}{ Tumor size (mm) } \\
\hline$<66$ & Reference & & Reference & \\
\hline$\geq 66$ & $1.468(0.840-2.566)$ & 0.177 & $1.617(0.866-3.017)$ & 0.131 \\
\hline \multicolumn{5}{|l|}{ Surgery } \\
\hline Yes & Reference & & Reference & \\
\hline No & $5.336(2.889-9.856)$ & $<0.001$ & $1.782(0.716-4.438)$ & 0.215 \\
\hline \multicolumn{5}{|l|}{ Radiation therapy } \\
\hline Yes & Reference & & & \\
\hline No & $1.162(0.547-2.464)$ & 0.696 & & \\
\hline \multicolumn{5}{|l|}{ Chemotherapy } \\
\hline Yes & Reference & & & \\
\hline No & $1.140(0.653-1.988)$ & 0.645 & & \\
\hline
\end{tabular}

CSS, cancer-specific survival; MFH-B, malignant fibrous histiocytoma of bone; HR, hazard ratio; Cl, confidence interval. 